\section{Author response-vitamin D deficiency and systemic inflammation in bronchiectasis}

Dr Charles Shee raises a further possible explanation for our finding of an association between vitamin $\mathrm{D}$ status and disease severity in bronchiectasis, that low vitamin D status represents a negative acute phase response to acute inflammation. ${ }^{1}$

Our study was cross-sectional and was unable to establish whether vitamin D deficiency is a cause or consequence of bronchiectasis. ${ }^{2}$ Possible explanations that have been previously suggested are failed bacterial clearance due to loss of the antimicrobial and immunomodulatory effects of vitamin $\mathrm{D}$, polymorphisms in the vitamin $\mathrm{D}$ binding protein gene that may affect macrophage function and the well-recognised association with reduced outdoor physical activity and dietary intake.

The acute phase response is unlikely to be the only explanation for the observed association with severity. We previously reported only a weak association between $\mathrm{C}$ reactive protein (CRP) and erythrocyte sedimentation rate, as acute phase reactants, and bacterial colonisation in bronchiectasis. $^{3}$ In the present analysis, adjusting for CRP while stable in the logistic regression model did not affect the association between vitamin $\mathrm{D}$ deficiency and bacterial colonisation (adjusted OR $1.6195 \%$ CI 1.03 to $2.51, \mathrm{p}=0.03$ ).
There was, however, a correlation in our study between stable CRP levels and severity of bronchiectasis by high resolution CT scan, as was shown in a previous study. ${ }^{4}$

Importantly, the study to which Dr Shee refers showed an effect of systemic inflammation on 25-hydroxyvitamin D (25-OHD) concentrations after major surgery, resulting in a mean CRP rise of $116 \mathrm{mg} / \mathrm{l}$ and a mean fall in 25-OHD of $10 \mathrm{nmol} / / .^{5}$ In our study and in the Wilson et al study, stable patients with bronchiectasis had a mean CRP level of $6 \mathrm{mg} / \mathrm{l}$. It is unclear whether such low-level systemic inflammation can also affect circulating 25 -OHD levels, but it is unlikely to be solely responsible for the degree of vitamin $D$ deficiency observed in our population.

Ultimately, as we suggest in the main article, only an intervention study will convincingly establish whether vitamin D replacement can improve clinical outcomes in bronchiectasis.

\section{James D Chalmers}

Correspondence to Dr James D Chalmers, Tayside Respiratory Research Group, University of Dundee, Dundee DD1 9SY, UK. jameschalmers1@nhs.net

\section{Competing interests None.}

Provenance and peer review Not commissioned; internally peer reviewed.

To cite Chalmers JD. Thorax 2013;68:679.

Received 13 December 2012

Accepted 14 January 2013

Published Online First 12 February 2013

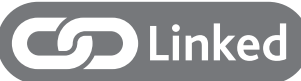

http://dx.doi.org/10.1136/thoraxjnl-2012-203189

Thorax 2013;68:679.

doi:10.1136/thoraxjnl-2012-203202

\section{REFERENCES}

1 Shee $C D$. Is hypovitaminosis $D$ a consequence rather than cause of disease? Thorax 2013;68:679.

2 Chalmers JD, McHugh BJ, Docherty C, et al. Vitamin-D deficiency is associated with chronic bacterial colonisation and disease severity in bronchiectasis. Thorax 2013;68:39-47.

3 Chalmers JD, Smith MP, McHugh B, et al. Short and long term antibiotic therapy reduces airway and systemic inflammation in non-CF bronchiectasis. Am J Respir Crit Care Med 2012;186:657-65.

4 Wilson CB, Jones PW, O'Leary CJ, et al. Systemic markers of inflammation in stable bronchiectasis. Eur Respir J 1998;12:820-4.

5 Gama R, Waldron JL, Ashby HL, et al. Hypovitaminosis $\mathrm{D}$ and disease: consequence rather than cause? BMJ 2012;345:e5706. 